\section{Observaciones respecto del turismo y el desarrollo territorial en contextos urbanos segregados: La paradoja de la inclusión de lo local}

Observations on tourism and territorial development in segregated urban contexts: The paradox of local inclusion.

\section{Patricio Espinosa*}

\section{Resumen}

La segregación socio-espacial en contextos turísticos es un fenómeno ampliamente estudiado por las ciencias sociales. Éstas, basadas principalmente en enfoques críticos, han puesto énfasis en observar la segregación socio-espacial y el turismo desde una dimensión material, lo cual dificulta conectar las reflexiones con el grado de abstracción necesario para comprender el fenómeno en su complejidad. De acuerdo con ello, se propone la aplicación de la teoría de sistemas sociales para caracterizar tanto al turismo como a la semántica del desarrollo territorial y, con ello, referirnos a la segregación socio-espacial vinculada al primado y función de ambos conceptos.

Palabras clave: turismo, desarrollo territorial, segregación socio-espacial, inclusión, exclusión.

\begin{abstract}
Socio-spatial segregation in tourism contexts is a phenomenon widely studied by the social sciences. Based primarily on critical approaches, their study has emphasized watching sociospatial segregation and tourism from a material dimension, making it difficult to connect the reflections with the degree of abstraction necessary to understand the phenomenon in its complexity. Accordingly, I propose the application of the social systems theory to characterize both tourism and the semantics of land development, and thus refer to the sociospatial segregation as linked to the primacy and role of both concepts.
\end{abstract}

Key words: tourism, territorial development, socio-spatial segregation, inclusion, exclusion. 


\section{Introducción}

El turismo es un fenómeno de relevancia social y económica que evolucionó a lo largo de los siglos XIX y XX para asentarse en prácticamente todos los rincones del mundo. Entre los factores que explican su crecimiento están el desarrollo de nuevas tecnologías de comunicación y transporte y el acceso a ellas, su habitual presentación como alternativa económica de bajos impactos socioambientales, la comunicación de escasez patrimonial y la consolidación de economías locales vinculadas a la industria del ocio (Santana 1997; Callizo 1991). Todas estas características han hecho del turismo una actividad que en la actualidad tiende a especializarse en torno a ámbitos de interés asociados a determinados atractivos, como el turismo comunitario, el turismo cultural, el turismo étnico y el turismo rural, entre otros, los cuales plantean y problematizan la inclusión de la población local como promotores y receptores de bonanzas económicas (Acuña 2012; Juárez 2012; Ojeda 2012; Yaukhana 2012; Inostroza 2008; Santana 2008; Schaerer y Dirven 2001).

No obstante, la literatura especializada señala al turismo como una actividad que genera múltiples efectos en los territorios de acogida (Fontes y Marinho 2011; Mazón, Huete y Mantecón 2009). Buena parte de estos efectos se vinculan a la naturaleza de la planificación turística, la que actúa relevando sólo ciertas áreas susceptibles de ser visitadas por los turistas (Aragón 2013; Antón 1998). En el caso del turismo urbano, este proceso lleva a la emergencia de fenómenos sociales suscitados en el seno de la planificación urbana, como la segregación socio-espacial (Zunino, Hidalgo y Marquardt 2011; Enríquez 2010; Díaz y Lourés 2010; Pérez
2010; Ibarra 2007; Díaz 2004). Como se verá en el presente trabajo, esta dinámica puede comprenderse mediante la observación de modelos de desarrollo territorial turístico que, no obstante la exclusiva y cuidadosa selección de elementos de interés para el visitante, obtenida como resultado de criterios estrictamente 'turísticos' que optan por excluir la precariedad característica de la población segregada, en sus programas, (fundamentados sobre la semántica del 'desarrollo'), incluyen discursivamente a los segmentos sociales segregados, muchas veces como agentes clave en el funcionamiento del turismo local o bien como depositarios de las bonanzas económicas forjadas con los atractivos. Surge, de este modo, la necesidad de discutir y reflexionar en torno a los conceptos de turismo y desarrollo para observar el fenómeno de la segregación socio-espacial en territorios con vocación turística.

En base a estas premisas, el artículo abre con la pregunta respecto de la función del turismo, para luego, en el segundo apartado, proponer un tratamiento teórico conceptual del turismo desde la teoría de sistemas sociales (Luhmann $2007,1997)$ como una posibilidad de encontrar en este enfoque el nivel de abstracción teórica suficiente para su comprensión en el seno de la complejidad social (Rodríguez y Arnold 2010). A continuación, en el tercer apartado, se presenta la segregación socio-espacial como un fenómeno que se vincula a la desigualdad social producida en el contexto de la diferenciación funcional (Arnold 2012), articulando su análisis a través del binomio inclusión/exclusión, para luego, en el cuarto apartado, discutir la relación entre la semántica del desarrollo territorial y la función del turismo para observar desde allí la segregación socio-espacial. Finalmente, se presentan las principales conclusiones. 


\section{El turismo como viaje de ocio}

El turismo es una actividad que surgió en Europa a fines del siglo XVIII, al alero de las transformaciones propias de la sociedad moderna. Dentro de las más importantes se encuentra la invención de nuevas tecnologías de transporte y comunicación traídas con la revolución industrial, que permitieron vencer el espacio-tiempo al acortar distancias (ferrocarril, vapores, telegrafía, entre otras). De la misma forma, fue clave la consolidación de los Estados modernos, pues con ellos se comenzaron a garantizar servicios de transporte y comunicación a partir de nuevos ordenamientos por país, resaltando, por cierto, aquellos elementos locales susceptibles de admiración (Turner y Ash 1991; Farías 2008).

La emergencia de la semántica del turismo se encuentra en la Gran Bretaña de 1700. Por aquel entonces, la juventud aristocrática británica acostumbraba a realizar el Grand Tour, un viaje que se efectuaba por los principales destinos artístico-culturales de la época como parte de un modelo educativo que contemplaba en el viaje un elemento fundamental en la formación del gent/man: "La palabra turista aparece en la época romántica. En primer lugar es un adjetivo. Califica al viajero inglés rico y curioso que con su guía visita lo que debe ser visto (...). No se trata de descubrir, sino de reconocer los lugares señalados" (Boyer 2002: 14).

Si desde los albores del turismo hubo actividades que concitaron la congregación de personas en demanda de servicios que poco a poco fueron conectándose con el ocio, éstas fueron el termalismo (Jarrassé 2002) y las actividades balnearias (Walton 2002; Laborde 2002). El termalismo fue una práctica clave en la génesis del turismo. Si bien su auge y primer desarrollo se encuentra en el siglo XVIII, la costumbre de visitar aguas termales se remonta a la Antigüedad, vinculándose a razones médicas, religiosas y de distinción social (Jarrassé 2002). El termalismo, ya en el siglo XVIII, favoreció la generación de modelos que instalaron circuitos de visita y atención especializada que poco a poco fueron circunscribiéndose al ocio de la población. Estos circuitos se fortalecieron con la aparición de guías de visita que permitieron conectarlos y comunicarlos de forma virtual. Uno de los primeros centros termales se encuentra en la ciudad de Bath, Inglaterra, lugar en donde para Boyer (2002) se origina la 'temporada termal', modelo que influirá en otras regiones con recursos termales como el centro de Spa, en Bélgica; Houmbourg, Aix y Vichy en Francia; Baden en Alemania y Montecatini en Italia. En España están Sacedón, Trillo, Marmolejo, Puente Viesgo y Solán de Cabras (Larrinaga 2002). Tal como el termalismo, el gusto por la playa habría surgido precisamente en la Inglaterra del siglo XVIII (Walton 2002), extendiéndose a otras costas de Europa occidental como Bélgica (Ostende), Francia (Boulogne) y España (Larrinaga 2002). Es en estas regiones donde se ubica la germinación de lo que a fines del siglo XVIII se entenderá como turismo.

Ya en los siglos XIX y XX es posible identificar algunos hitos que tributaron en la conformación del turismo como resultado de emprendimientos públicos y privados. En 1874, el empresario inglés Thomas Cook crea los cheques de viaje (travellers checks), y en 1851 funda la primera agencia de viajes organizados: la Thomas Cook and Son, con la que promociona diversos viajes en tren por Inglaterra. En América, William Cody (también conocido como Bufalo Bill) instala la primera exhibición sobre el Far West, 
escenificando la figura del vaquero, de los pobladores originarios locales, de la conquista y la fauna característica del oeste estadounidense (Santana 1997). Hacia fines del siglo XIX, la masificación del automóvil también contribuyó a facilitar traslados al independizar a los sujetos de programaciones horarias del transporte público. Se funda The British Touring Club en Inglaterra y el Touring Club y el Automovil Club de Francia. A fines del siglo XIX se comienzan a practicar deportes de alta montaña en época invernal, costumbre que antes de 1880 sólo era realizada en época estival (Boyer 2002). Por aquellos años, el famoso empresario hotelero Charles Ritz construye el Gran Hotel de Roma (1893), el Hotel Ritz de Paris (1898) y el Carlton de Londres (1899), íconos de la hotelería mundial. Fue gracias a estos procesos que se fue incorporando un nuevo sentido al viaje, el cual refiere al viaje de ocio como un fin en sí mismo. Este sentido permite distinguir al turista como un personaje particular respecto de otros personajes históricos relacionados con el viaje (Farías 2008; Boyer 2002). Así, para el comerciante, el peregrino o el conquistador medieval el viaje habría poseído un sentido programático que se escinde de la posibilidad de ocio: se viaja con fines económicos, religiosos, militares o políticos. Sólo la Modernidad será testigo de un tipo de comunicación que se orienta a probabilizar el viaje de ocio: el turismo.

En su génesis, el turismo fue una actividad elitista, manteniéndose de esa forma hasta bien entrado el siglo XX. La inclusión de las clases populares se inicia con el descanso programado (Callizo 1991), específicamente con la entrada en vigencia del derecho a vacaciones pagadas suscrito a la Convención $N^{\circ} 52$ de la Organización Internacional del Trabajo en 1936. De esta manera, su consolidación, ahora como fenómeno social transversal, es el resultado de conquistas de derechos laborales (Santana 1997; López 2002). Sin embargo, su despegue como actividad de masas será progresivo hasta llegada la década de 1950 (Boyer 2002; Gordon 2002). Se comienza a gestar y a consolidar una actividad que se fundamenta en el viaje de ocio ante las necesidades de descanso y esparcimiento de la sociedad industrial. Nuevas tecnologías de transporte y permanentes acciones para resaltar identidades nacionales contribuyeron a la generación de una nueva semántica para el viaje y nuevas perspectivas de observación del mundo fundadas en la patrimonialización (De Esteban 2008; Gómez 2004). Gordon (2002) seña que "[e]l turismo es la expresión práctica de la curiosidad. Es la expresión de los valores estéticos; la gente va para conocer lo bello, lo deseado, lo interesante. El turismo es aquello que expresa en la practica la estética cultural" (125).

Como se ha señalado, el viaje se llevó a cabo durante muchos siglos sin ninguna relación especial con el ocio, vínculo que comienza a forjarse en la Modernidad. Precisamente, la semántica del ocio se corresponde con las transformaciones sociales que acaecieron con la revolución industrial. Ello debido a que, no obstante la gran variedad de actividades artísticas, festivas y deportivas vinculadas a los usos del tiempo libre observables en épocas anteriores a la Modernidad (Elias y Dunning 1992), fue justamente en este período en que la alternancia entre trabajo y descanso permite distinguir al ocio como el tiempo libre de la sociedad industrializada (Burke 1997, 1995).

En la obra de Marx el ocio no fue un campo específico de reflexión. Sin embargo, es posible inferir que para este autor el ocio dependería de 
la infraestructura material, por lo que la clase obrera no poseería formas de ocio susceptibles de simbolizar. Desde esta perspectiva, el don benéfico atribuido al trabajo generaría opacidad en la comprensión del ocio. Compartiendo la misma preocupación por la cuestión obrera, y ciertamente con un particular sello personal, Lafargue (1907) cuestiona el sentido del trabajo para la clase obrera, proponiendo quitarlo como su piedra angular. Frente a ello, concibe al ocio como la verdadera búsqueda en la que debe ocuparse el proletario: "es necesario que el proletariado pisotee los prejuicios de la ética cristiana, económica y librepensadora. Es necesario que vuelva a sus instintos naturales, que proclame los Derechos a la pereza, mil veces más nobles y sagrados que los débiles Derechos del hombre"1 (Lafargue 1907: 29). Para Weber (1991), a partir de la relación dada entre los fundamentos de la ética protestante y el desarrollo del capitalismo, el ocio, al igual que en Marx, también ocuparía un lugar marginal en la sociedad, puesto que sería el lado opuesto de los valores asociados al trabajo y la acumulación de capital que caracterizaban a la burguesía protestante de la época.

Hacia fines del siglo XIX, Veblen (2004) efectuó uno de los primeros trabajos sociológicos vinculado al estudio de ocio. Para dicho autor, el ocio es un producto evolutivo que surge al alero de la propiedad, siendo patrimonio exclusivo de las clases dominantes. Con estas premisas, el ocio se vincula a la idea de pasar el tiempo sin hacer nada productivo, poseyendo ante todo un carácter funcional a las clases dominantes, al permitirles alejarse del trabajo y demostrar su capacidad pecuniaria. Con ello, el ocio para Veblen (2004) es una especie de símbolo de

\footnotetext{
Traducción propia del inglés al castellano.
}

distinción social presente en estilos de vida de las altas clases sociales. En esta línea, también Bourdieu (1998) señala que las clases sociales altas crean el gusto a modo de mecanismo de distinción social respecto de las clases sociales populares. Se infiere del autor francés que el ocio estaría estrictamente vinculado con la posesión de capital, el que tributaría a habitus distintivos en relación a las prácticas y actitudes hacia el tiempo libre.

Por otro lado, Horkheimer (Mantecón 2008) postula que desde la sociedad industrial decimonónica la vida del individuo está en gran medida determinada por las premisas del capitalismo. De aquí se comprende al ocio como mecanismo que surge desde y para el capitalismo como una forma de atender a las necesidades de reposo de la masa trabajadora sin alterar la productividad. En una línea similar, para Sue (1987) el ocio se refiere a la posibilidad de experimentar libertad por medio del cese de las actividades cotidianas en la sociedad capitalista, poseyendo funciones psicológicas (descanso, diversión y desarrollo personal), sociales (sociabilidad, simbólicas y terapéuticas) y económicas (vinculada al consumo).

El viaje y el ocio son conceptos clave que se encuentran desde los primeros a los más actuales trabajos teóricos del turismo (Fernández 1991). Por muy divergentes que puedan ser las concepciones de turismo, lo cierto es que en la gran mayoría de los autores es posible identificar ambos conceptos clave en sus respectivas definiciones. Prácticamente durante toda la primera mitad del siglo XX dominaron concepciones de turismo que pusieron su acento en las motivaciones del viajero y el contexto de llegada, desprendiéndose de ellos análisis que pondrán atención en consecuentes 
efectos económicos, sociales y culturales desde posiciones encontradas. No obstante, a partir de la década de 1960 los investigadores interesados por la comprensión del turismo comienzan a observarlo a la luz de la teoría general de sistemas (Von Bertalanffy 1989), enfoque que permitió, mediante la aplicación de sus premisas teórico-conceptuales, llevar el análisis del turismo a un nivel de mayor complejidad (Vásquez et al. 2013).

En síntesis, el viaje de ocio es la base conceptual del turismo. Se trata de un viaje, por cuanto implica la posibilidad de desprendimiento temporal del hábitat cotidiano. Independiente de su duración o del destino, el turismo es un viaje motivado por el ocio, es decir, por la posibilidad de escisión temporal de las actividades cotidianas. Por ende, turismo es, ante todo, la comunicación del viaje de ocio en sí mismo. Como se señaló al comienzo, siguiendo a Farías (2008), el concepto de turismo surge para probabilizar el viaje de ocio en el seno de la sociedad moderna. Diremos, pues, que con el turismo el viaje y el ocio se compatibilizan, permitiendo así comunicar a la otredad como atractivo (Farías 2014).

\section{Teoría de sistemas sociales y turismo}

Por lo general, el turismo ha sido descrito como una actividad eminentemente económica que ha sido entendida sobre la base casi exclusiva de oferentes y demandantes de servicios turísticos (De Esteban 2008). Ello ha generado diversas definiciones y enfoques de análisis que ofrecen una comprensión ligada a dimensiones empíricas, permitiendo observar tal fenómeno sólo de manera parcial, supeditado a la corriente ideológica de los autores y al análisis de casos.
No obstante lo nutrido de estos trabajos y sus contribuciones, tales perspectivas limitan la comprensión del turismo como un fenómeno propio de la sociedad moderna (contemporánea), esto es, como un fenómeno sujeto a la complejidad. Por ello, pensar un fenómeno social en el marco de los desafíos al entendimiento que emergen desde la sociedad requiere enfoques teóricos que consideren la naturaleza elemental de las operaciones sociales, permitiendo así al investigador abordar problemáticas sociales estando consciente de la complejidad implicada en la lectura de su entorno. Con teorías que brinden 'consciencia de complejidad', el turismo efectivamente puede asomar como un fenómeno cuya comprensión primordial pasa por poner en discusión el patrimonio teórico de la ciencia social para luego forjar nuevos derroteros de análisis. A ello responde la elección de la teoría de sistemas sociales para caracterizar al turismo, con la posibilidad de generar mayor abstracción teórica en su comprensión y así escindirse de las dimensiones objetuales que han dirigido buena parte de las nociones de turismo con que han tratado las ciencias sociales, como puede observarse en las etapas de pensamiento científico volcado al turismo que identifica Fernández (1991) o con las plataformas de observación del turismo de Jafari (1994). Tanto conceptos como el propio viaje o el ocio, así como el tiempo libre, la autenticidad, las actividades extracotidianas, la estructura turística o el patrimonio cultural y natural, entre otros, son más bien comunes a la hora de caracterizar esta compleja actividad, los que con un especial énfasis en aspectos económicos (De Esteban 2008) han posibilitado el desarrollo de variadas rutas reflexivas, sobre todo respecto de procesos socioculturales en contextos de llegada. Si bien todos los conceptos que antes señalábamosson insoslayables para comprender 
al turismo como una actividad distintiva de la sociedad contemporánea, su análisis perdería rendimiento teórico si nos remitimos a éstos con la pretensión de caracterizar un fenómeno altamente complejo, cuya comprensión escapa a consideraciones estrictamente locales.

Los primeros trabajos volcados al estudio del turismo desde la teoría de sistemas sociales emergen hacia la mitad del siglo XX (Vásquez et al. 2013; Serrano et al. 2012). Estos trabajos, en su mayoría, se basaron en la teoría general de sistemas de Von Bertalanffy (1989), quien estaba interesado en la comprensión de fenómenos biológicos intentando superar reduccionismos mecanicistas. Para este autor, la perspectiva sistémica era capaz de ofrecer un enriquecedor marco teórico-conceptual en la comprensión de fenómenos de naturaleza animada, y es así como postuló la necesidad de unificar diversas disciplinas científicas a través de una teoría general de sistemas.

El sistema para Von Bertalanffy (1989) es "un conjunto de elementos en interacción" (38) que opera a través de relaciones entre input (entrada) y output (salida) para procesar la información que proviene del ambiente. El ambiente, por su parte, es entendido como una dimensión que influye en los procesos bioquímicos del organismo. Se fragua, de esta manera, una teoría que observa al sistema en una perpetua e indisoluble relación con un determinado entorno. Con ella, la explicación de un fenómeno se situará en la relación dinámica y recíproca dada entre la estructura del sistema y sus conexiones con el ambiente.

Esta teoría ofrece un enfoque totalizador para el estudio del fenómeno turístico. Con él, el turismo se entenderá como sistema abierto, en el cual el equilibrio es el eje basal de análisis que se obtiene a partir de la relación recíproca de distintos componentes: el visitante, el residente, la oferta hotelera, el patrimonio y la infraestructura, elementos que en su conjunto permitirán definir la competencia turística de un territorio. En esta línea argumental, Molina y Rodríguez (2005) señalan que el turismo puede ser observado desde tres perspectivas: como industria, como fenómeno social y como sistema. Con esta conceptualización, los autores aluden a un mecano socioeconómico (industria) en el cual tiene sentido la manifestación del ocio ligada al tiempo libre (fenómeno social), pudiendo observarse en esta relación una serie de componentes vinculados entre sí (sistema). A estas subpartes las identifican como la superestructura, la demanda, la infraestructura, los atractivos, los equipamientos y la comunidad receptora. Se obtiene así una concepción de turismo caracterizada como sistema abierto, entre cuyos componentes se encuentran elementos de diversa naturaleza que interactúan entre sí.

Esta será la tónica que acompañará los distintos trabajos inscritos en la teoría general de sistemas. Autores como Mathienson y Wall (1982), Cohen (1984) y Sessa (1985) (en Vásquez et al. 2013: 6) conciben el turismo desde una perspectiva totalizadora, comprendida a partir del análisis de diversas variables que influyen directa y coordinadamente en su dinámica. Se identifican, en primer lugar, los elementos que componen al sistema turístico, y luego se ponen en relación con las relaciones socioterritoriales que definen y orientan el carácter turístico de un determinado territorio. El enfoque de sistemas abiertos permite comprender al turismo como una actividad cuyo sentido se construye a través de la relación recíproca de diversos elementos 
que forman parte de un todo. Este enfoque pone atención en dimensiones objetuales y sociales interrelacionadas, las que se articulan en función de una determinada oferta, una determinada demanda y un determinado mecanismo políticoeconómico que lo fundamenta, y por ende, dinamiza.

No obstante, en el presente artículo se opta por caracterizar al turismo desde la teoría de sistemas sociales de Niklas Luhmann (2007), pues el nivel de abstracción que ofrece su arquitectura teórico-conceptual nos permite observar al fenómeno turístico más allá de ciertos componentes. A este autor se debe el desarrollo de una sofisticada visión de la sociedad moderna, en cuya base se sitúa la epistemología constructivista (Arnold 2010), la cual es heredera de disciplinas abocadas a la comprensión de la naturaleza de la vida y de la cognición, como la biología del conocimiento de Maturana y Varela, la cibernética de segundo orden de Von Foerster y la lógica de las formas de SpencerBrown (Rodríguez y Arnold 2007). Tomando los recursos teóricos del constructivismo, Luhmann propone superar la dicotomía sujeto/objeto en la investigación, autoimplicando al investigador en todo proceso de conocimiento. En este sentido, para el autor alemán no existe correspondencia entre la observación y una realidad externa que viva con independencia de quien observa. En otras palabras, toda experiencia de mundo es experiencia construida.

Este autor propone pasar de comprender a la sociedad como un todo a observarla desde una primera distinción: la diferencia entre el sistema y su entorno. El sistema para Luhmann (2007) es una unidad de sentido autorreferencial y autopoiética constituida siempre con un respectivo entorno, el cual permite distinguir al sistema del límite al cual no pertenecen sus operaciones. La diferencia entre sistema y entorno supone su reproducción a distintos niveles dentro del sistema sociedad, y estos niveles están dados por la emergencia de tres tipos de sistemas sociales, a saber: la interacción, la organización y la propia sociedad. La interacción utiliza la co-presencia de personas como criterio de delimitación comunicando temas; la organización se delimita en torno a una membresía comunicando decisiones mientras que la sociedad es el sistema que comprende todas las comunicaciones. La sociedad moderna -o contemporánea- es el tipo de sociedad que se organiza en torno a la diferenciación funcional $\mathrm{y}$, mediante este primado, atiende a sus problemáticas a través de diversos sistemas parciales vinculados a funciones específicas, como el sistema educativo, el sistema político, el científico o el económico. Cada sistema funcional opera a partir de un código que le permite probabilizar la comunicación, siendo la comunicación el único elemento de naturaleza estrictamente social (Luhmann 2007). Cada sistema observador, entonces, observará/ distinguirá un fenómeno de acuerdo a sus propias operaciones recursivas. En consecuencia, toda observación es eminentemente autorreferente y contingente, lo que implica que cuando el sistema reduce la complejidad mediante operaciones de actualización de sentido a la vez está incrementándola, pues este procesamiento de complejidad implica una multiplicidad de observaciones clausuradas en sus operaciones: el turismo, como observación/distinción sistémica puede ser descrito de múltiples posibilidades.

Cabe señalar que Luhmann no escribió sobre turismo. Solo se conoce una referencia en una de sus obras: Los Derechos Fundamentales como 
Institución (Luhmann 2010), en cuyo prólogo, escrito por Klaus Dammann, se constata la existencia de trece sistemas funcionales entre los que se cuenta el turismo². Este tratamiento, más bien tangencial, ha impedido un desarrollo conectado directamente con el pensamiento del autor, lo que sin lugar a dudas representa una debilidad a la hora de concebir la complejidad que reviste tal fenómeno desde la óptica del genio creativo de Luhmann (Pérez y Labraña 2013).

Ahora bien, si se intenta pensar en el turismo como un sistema clausurado operativamente, se debiese, en primer lugar, identificar un problema (entorno) y su tratamiento a través de un código. El problema al cual bien podría abocarse un supuesto sistema turístico sería el del viaje de ocio, y su respectivo código sería viaje de ocio/ no viaje de ocio. Llegado este punto, surge una dificultad para entender al turismo como sistema operativamente clausurado: su código plantearía la interpenetración de otros códigos para un funcionamiento (viaje + ocio), por lo que la posibilidad de establecer dicho código -un solo código- se desvanece. Por ende, el viaje de ocio pensado como código es demasiado amplio, por cuanto la posibilidad/imposibilidad del viaje de ocio nos remite a la autopoiesis de otros sistemas funcionales. Así, el turismo "tiene variadas expresiones que no quedan clausuradas en la sola realización del viaje de placer, por lo que (...) no logra una clausura operativa y no constituye un sistema societal" (Osorio 2004: s/p).

Esto lleva a pensar que el turismo se correspondería, más bien, con la operación de

Incluyendo al turismo, estos son: el deporte, el ejército, la religión, la educación, la ciencia, los medios de masas, el arte, la economía, la política, la medicina, la intimidad (familia) y el derecho. observación/distinción de los sistemas, los que mediante sus respectivos códigos permitirían la probabilización del viaje de ocio. Osorio $(2007,2004)$ plantea la posibilidad de observar al turismo como una distinción efectuada por distintos sistemas funcionales, descartándolo así como sistema operativamente clausurado. Con esta salida, el concepto de turismo ya no asoma como totalidad compuesta por partes coordinadas en atención al viaje turístico, lo cual lleva a observar el fenómeno turístico más allá de la relación de diversos elementos constituyentes. Con esta consideración, el turismo puede ser comprendido como distinción que se actualiza en la estructura del sistema observador, por lo que el procesamiento de su complejidad pasa por las operaciones recursivas de ese sistema observador.

La comunicación turística para esta autora se articula a través del binomio viaje turístico/ no viaje turístico, entendiendo al viaje turístico como viaje de placer. El placer, en consecuencia, es observado como la categoría que permite diferenciar al turismo con otros tipos de viaje (Osorio 2004). De acuerdo con ello, cada uno de los sistemas funcionales observaría/distinguiría al turismo como la unidad de la diferencia entre viaje turístico/no viaje turístico, por lo que la evolución del turismo está sujeta a la autopoiesis de los sistemas funcionales.

Sin embargo, coincidiendo con Farías (2008), el concepto 'placer' plantea mucha ambigüedad como categoría analítica para el estudio del turismo. Así también la categoría viaje turístico/ no viaje turístico, por cuanto el lado no marcado de la comunicación turística no remite a espacios no turísticos como sugiere Osorio (2004), sino más bien a extensión turística latente, esto es, por visitar. En otras palabras, la comunicación 
turística se articula en función de un continuum turístico, que remite, por ejemplo, a la idea de otros destinos turísticos, y no a otras formas de construcción territorial en oposición a aquellos de vocación turística. Es así como Farías (2008) propone el binomio turistear/vacacionar como distinción directriz de la comunicación turística. Con turistear refiere al campo semántico de la diferencia, esto es, lo desconocido, aquello que se descubrirá en el viaje turístico. Por su parte, vacacionar indica la semántica de la igualdad, de lo conocido o aquello familiar o familiarizable en el viaje turístico. La distinción turistear/ vacacionar implica la división de un ámbito de contingencia en la comunicación turística; vale decir, se trata del código a la base de este tipo de comunicación, el cual permite observar al turismo como medium, uno que permite probabilizar el viaje de ocio.

Plantear al turismo como medium, esto es, como una distinción contingente y débilmente acoplada a estructuras de sentido (Corsi, Espósito y Baraldi 1996), supone un concepto de turismo que se escinde de la posibilidad de considerar al territorio como dimensión predeterminada por la comunicación turística. El turismo actualiza sentido probabilizando el viaje de ocio y, mediante esta operación, duplica al mundo como horizonte turístico conocido, familiar y desconocido mediante el código vacacionar/turistear.

Con lo anterior se propone observar al turismo como medium cuya función es la probabilización del viaje de ocio. Con ello se obtiene que el destino turístico no remite a un espacio preexistente ni condicionante para el turismo, pues es actualizado como operación contingente de la comunicación turística. Así, la definición turística de un territorio se comprende como una operación que, mediante el medium turismo, remite al esquema de distinción del sistema observador.

\section{EI problema de la integración: la segregación socio-espacial}

Mediante el concepto de segregación socioespacial se remite a uno de los varios ejemplos que en la sociedad funcionalmente diferenciada (Luhmann 2007, 1997) pueden tener correlato con la idea de desigualdad (Arnold 2012). Específicamente, nos referimos al problema de la distribución y ocupación del espacio urbano como expresión objetual de la diferenciación entre estratos sociales (Torche 2006).

El concepto de segregación socio-espacial refiere a una manera de dar sentido al espacio que posee sintonía con la semántica de la exclusión. La segregación socio-espacial es un fenómeno muy extendido entre las urbes latinoamericanas (Sabatini, Cáceres y Cerda 2001; Marengo 2004), y apunta a aquellas dinámicas suscitadas por la separación espacial de grupos sociales de altos ingresos económicos respecto de aquellos con bajo poder económico, escisión que tiene entre sus causas las políticas de planificación urbana basadas en la exaltación del casco urbano consolidado, en la liberalización del mercado de suelos, en la especulación del mercado inmobiliario y también en la reafirmación identitaria de grupos sociales emergentes (Garín, Salvo y Bravo 2009). En esta línea, siguiendo a Sabatini (2006), se pueden establecer tres dimensiones diferenciadas de la segregación socio-espacial en las cuales se observan sus impactos a nivel social, urbano y político respectivamente. Éstas son: "el grado de concentración espacial de los grupos 
sociales; la homogeneidad social que presentan las distintas áreas internas de las ciudades; y el prestigio (o desprestigio) social de las distintas áreas o barrios de cada ciudad" (Sabatini 2006: 7). Así, el concepto de segregación socioespacial se refiere a una especial dinámica de auto y heterorreferencia de grupos sociales carentes respecto a su distribución y sentido de pertenencia con el espacio.

Ahora bien: ¿de qué manera es posible comprender la segregación socio-espacial en contextos de vocación turística?, ¿la comunicación turística y la semántica del desarrollo territorial soportan la segregación socio-espacial? Como hemos señalado, para Luhmann $(2007,1997)$ la sociedad moderna se caracteriza por la diferenciación funcional. Es decir, por atender a sus problemáticas mediante sistemas funcionales especializados que se clausuran en torno a un código y programa específico. La diferencia, observada desde el sistema, se refiere a la reproducción sistema/ entorno dentro del sistema, proceso a través del cual se obtienen dos tipos de entornos: uno que se corresponde con las operaciones exclusivas del sistema (entorno interno) y otro que es común para todos los sistemas (entorno externo). De ello se obtiene que cada sistema funcional opera de manera autorreferencial tanto para observar su entorno interno como para observar las operaciones de otros sistemas funcionales, vale decir, reproduciendo la diferencia sistema/entorno mediante sus propios criterios de observación/distinción. Así, el principal problema de la sociedad diferenciada por funciones es el de la indiferencia del sistema respecto de las operaciones de otros sistemas (Luhmann 1994), los que, no obstante, son presupuestos como parte del funcionamiento de la sociedad: "todos los sistemas funcionales reclaman universalidad -aunque tan solo para su ámbito correspondiente (...) de esto resulta que una semántica de la sociedad total necesita combinar universalismo de los potenciales de tematización con especificación de las referencias sistémicas" (Luhmann 2007: 780). De este modo, la complejidad de la sociedad contemporánea deviene en que la naturaleza de las operaciones de los sistemas funcionales, en atención de los problemas de su entorno, les impide observar/distinguir otro tipo de comunicación que no sea aquella que concita su específica función codificada. Es decir, los sistemas funcionales "no consideran nada más allá de las premisas con las cuales se regulan" (Arnold 2012: 36). Con lo señalado, se obtiene que la sociedad contemporánea renuncia a la posibilidad de observar de manera íntegra y unitaria los fenómenos de su entorno, de modo que su condición policontextual conlleva a que la integración opere a través de mecanismos de inclusión/exclusión (Arnold 2012).

El binomio inclusión/exclusión que desarrolla Luhmann (2007) es el fruto de sus reflexiones a la luz de la teoría de la forma de G. Spencer Brown, la cual se refiere a que las operaciones del sistema, en tanto observaciones/ distinciones, siempre dividen al mundo en la unidad de dos lados: el incluido y el excluido. El lado incluido es aquel donde precisamente el sistema actualiza el sentido que se presenta como base para las actualizaciones posteriores, mientras que el lado excluido queda opacado. Con este postulado, Luhmann (1997) se aleja del enfoque que ve en la integración normativa el eje central de la sociedad, como lo sostuvo Durkheim a través del principio de la moral, o como lo desarrollaron tanto Parsons como Habermas, para quienes la inclusión debía entenderse como la consecuencia de acciones 
individuales unidireccionales dispuestas para la aceptación y la posterior integración en el sistema (Luhmann 1998; Robles 2000).

Tomando en cuenta que para la teoría de sistemas sociales los sujetos se sitúan en el entorno de los sistemas (Dockendorff 2013; Izuzquiza 2008), la relevancia de la forma inclusión/exclusión radica en la posibilidad de que estos distingan como personas a los sujetos (Cadenas 2012; Corsi, Espósito y Baraldi 1996), pues esta operación es, ante todo, un proceso contingente sujeto a la recursividad propia del sistema. Con las características de la diferenciación funcional, la inclusión debe observarse de manera parcial según opere cada sistema funcional. Al contrario, en las estructuras anteriores a la sociedad moderna, las formas de inclusión/exclusión se muestran, más bien, diáfanas y sedimentadas.

Como se desprende de la tabla 1, las formas de inclusión y exclusión en la sociedad funcionalmente diferenciada son susceptibles a tomar variados matices al estar supeditadas a las operaciones especializadas de cada sistema. Al operar bajo el principio de la diferenciación funcional, en consecuencia, no es posible concebir a la sociedad como una entidad que resuelva y trascienda a los diversos problemas sociales. Al contrario, el tratamiento de problemáticas sociales específicas queda en manos de cada sistema funcional, los que mediante mecanismos de inclusión/exclusión permiten que las personas participen o no de sus prestaciones. Así, siguiendo a Cadenas (2006), concordamos en que "la sociedad moderna (...) no resiste la integración por la vía de algún sistema social que racionalice como operaciones propias el mantenimiento de la estructura social como un todo estable e inmutable" (265).

Entonces, la posibilidad de una sociedad integradora en todos sus niveles es, a lo menos, cuestionable, pues la sociedad contemporánea es capaz de producir desigualdades como parte de las operaciones 'normales' del sistema. Precisamente Robles (2000), poniendo atención a las sociedades de la periferia moderna, reflexiona en torno a lo paradojal y abismal que resultan en ella los distintos procesos de inclusión y exclusión. Asimismo, Cadenas (2012) sugiere que en toda forma de desigualdad es posible encontrar tanto inclusiones como exclusiones, ocurriendo lo mismo si deseamos observar el lado de la igualdad. Tal como señala

Tabla 1. Formas de diferenciación basadas en la inclusión/exclusión

\begin{tabular}{ccc}
\hline Forma de diferenciación & Inclusión & Exclusión \\
\hline Sociedad segmentaria & Inclusión hacia el interior del sistema & Exclusión del entorno (otras sociedades) \\
Sociedad estratificada & Inclusión en el estrato alto del sistema & Exclusión del estrato bajo del sistema \\
Sociedad centro/periferia & Inclusión en el centro del sistema & Exclusión de la periferia del sistema \\
Sociedad funcionalmente diferenciada & Inclusión en cada sistema & Exclusión de cada sistema parcial \\
\hline
\end{tabular}


Arnold (2012): "Los individuos pueden estar incluidos parcialmente y, a la vez, parcialmente excluidos, o a lo largo de sus vidas experimentar multiinclusiones y multiexclusiones" (37).

Sin embargo, esta especial dinámica de auto y heterorreferencia aplicada a la observación de la segregación socio-espacial tomará un cariz igualmente particular si la vinculamos a un modelo de desarrollo territorial que se fundamenta en el turismo. Esto debido a que la semántica del desarrollo, orientada por el medium turismo, genera tensiones en torno al rol del asentamiento segregado en un contexto definido como destino turístico. Hablamos, pues, de un proceso complejo que involucra mecánicas específicas de inclusión y exclusión, pero que sólo son visibles a partir de un análisis susceptible de separar e igualmente poner en relación al medium turismo con la semántica del desarrollo, tal como lo intentaremos realizar a continuación.

\section{Desarrollo territorial y turismo}

Desde fines de la Segunda Guerra Mundial, el desarrollo ha sido el concepto eje que ha guiado las políticas nacionales de los países del mundo occidental. Desde entonces, ha otorgado dones benéficos a los procesos de industrialización y urbanización asociados a fuertes inversiones de capital (Violá 2000; Escobar 2007; Boisier 2003). Se conecta con las nociones de progreso y modernidad, pudiendo entenderse como la actualización semántica del primero y una etapa históricamente situada del segundo, lo cual implica que se observe como una condición de la humanidad, como resultado del despliegue de la razón y, además, que se valore favorablemente (Meyer 2013).
El desarrollo es, ante todo, un discurso que comunica futuro, el cual se articula a través de una promesa de bienestar social que releva la transición -o consolidación- de una economía industrial y capitalista (Violá 2000), siempre mediada por aparatos políticos, teóricos y administrativos que confirman al progreso como su piedra angular y a la modernización como un modelo de sociedad deseado.

La comunicación acerca de un futuro promisorio es resultado de la complejidad de la sociedad moderna. Mientras en estadios anteriores a ésta (tabla 1), se autodescribía, más bien, de manera unívoca y coherente. La sociedad funcionalmente diferenciada pierde esa capacidad, pues, dado su carácter policéntrico, la complejidad es ahora procesada de manera particular por cada uno de sus 'centros':

\begin{abstract}
se obtiene la impresión de que en torno a 1800 la imposibilidad de describir correctamente las nuevas estructuras de la sociedad moderna se ve compensada por proyecciones de futuro. Todavía hasta entrado nuestro siglo se habla del proyecto inconcluso de la modernidad y se exige más democracia, emancipación, más posibilidades de autorrealización, pero también más y mejor técnica -en pocas palabras: más de todo aquello que se había prometido como futuro. Tanto en lo tecnológico como en lo humano, la sociedad se describe mediante proyección de su futuro (Luhmann 1997: 125).
\end{abstract}

Implica que la sociedad moderna, desbordada por el procesamiento y emergencia de complejidad en el seno de sus sistemas funcionales, busca sus soluciones, y ciertamente el entendimiento de su estructura mediante referencias de futuro. La referencia temporal a un futuro 'promisorio' y 'comprensivo' permite la constitución de categorías semánticas para la observación/distinción del pasado mediante actualizaciones contingentes. Desde ahí pueden derivar visiones que planteen, por ejemplo, la posibilidad de generar integración social o 
superación de la pobreza a través del turismo inserto en un modelo de desarrollo.

Como ya lo hemos mencionado, si atendemos las características de la sociedad funcionalmente diferenciada, la idea de articular un sentido común unitario pierde consistencia. De aquí se obtuvo una primera implicancia: la sociedad moderna ya no puede describirse de manera unitaria, pues cada uno de los sistemas funcionales comunicará autorreferencialmente 'lo social'. Y si agregamos que cada uno de estos sistemas enlaza comunicaciones de manera contingente, tampoco es posible pensar la sociedad estableciendo conceptualizaciones últimas o teleológicas.

Tomando en cuenta que la sociedad moderna establece al binomio inclusión/exclusión como la principal de las distinciones (Labraña et al. 2012), la posibilidad de participar o no en las prestaciones de los diversos sistemas funcionales se juega por cuestiones de diferenciación estructural, por lo cual, si bien se puede participar en la comunicación de todos los sistemas funcionales, de ningún modo es posible formar parte integral de ninguno de ellos.

En consecuencia, a la imposibilidad de concebir la sociedad de manera unitaria y fija, se suma una tercera característica: la imposibilidad de concebirla desde un principio integrador. En este mismo sentido, Nassehi (2011) resalta el carácter estrictamente operativo y contingente de la sociedad, y por medio del concepto de 'sociedad de presentes' destaca que "en la sociedad moderna, funcionalmente diferenciada, diferentes contextos funcionales corren simultáneamente (...) y se sustrae con ello, tanto la capacidad de control mutuo, como de la coordinación de futuros compartidos" (8).
Se obtienen, de esta manera, tres principios característicos de la sociedad moderna mediante los cuales emerge la complejidad, la cual, excediendo sus posibilidades de aprehensión, obliga al establecimiento de comunicaciones de futuro. Una autodescripción unitaria, establecida bajo criterios fijos e integradores de los sujetos, es lo contrario a lo que precisamente puede observarse en la sociedad. $Y$ es aquí donde se inscribe la emergencia del discurso modernizador y su variante, el desarrollo, el cual puede comprenderse como un discurso que emerge frente a la necesidad de descomplejizar la sociedad en vistas a comprenderla y tratar sus problemáticas a partir del nuevo escenario mundial instalado luego de la Segunda Guerra Mundial. Su semántica distingue a la sociedad a partir del binomio desarrollo/subdesarrollo, siendo el primero aplicado a la observación de las características más cercanas a las potencias económicas, mientras el segundo, aplicado para observar aquellos elementos sociales, políticos y económicos que caracterizan a los países de la periferia capitalista. En la literatura especializada podemos encontrar diversas descripciones de esta complejidad orientadas por el binomio desarrollo/ subdesarrollo. Ya sean reflexiones en torno a los procesos económicos y productivos en contextos de la periferia capitalista (Ferro 2011) o del primer mundo (Clarke, Gaile y Saiz 1999; Benko 1998; Vásquez 1996); ya sea que aborden problemas de desigualdad (Flores 2005; Díaz 2006; Segovia y Jordan 2005), que planteen la necesidad de potenciar el desarrollo (Comisión Económica para América Latina y el Caribe [CEPAL] 1996), o de articularlo a través de modelos alternativos (Alburquerque 2004; Boisier 2001; CEPAL 1991) son algunos ejemplos que dan cuenta, con distintos ángulos, de diversas problemáticas sociales que surgen como expresión de complejidad en la sociedad moderna. 
El concepto de desarrollo, en consecuencia, opera comunicando un futuro a través de la observación de una red de procesos de inclusión/exclusión respecto a las prestaciones de los distintos sistemas funcionales. En el lado de la inclusión se distinguen aquellos elementos, valores y experiencias basados en las premisas de la modernidad, como la producción de riqueza, la ciencia, la tecnología y el control de la naturaleza, mientras que en el lado de la exclusión entran elementos, valores y experiencias vinculados a sociedades pre-modernas. A nivel global, el concepto de desarrollo divide al mundo fijando niveles de inclusión/exclusión respecto de las premisas modernizantes, las que, a su vez, son aplicadas para distinguir características societales a nivel local y regional. Al respecto, apunta Violá (2000):

\begin{abstract}
Pero si el concepto de desarrollo ha llegado a convertirse en una palabra-fetiche, no es porque describa con precisión una categoría coherente de fenómenos socialmente relevantes, sino porque siendo uno de los conceptos del siglo XX más densamente imbuidos de ideología y de prejuicios, ha venido actuando como un poderoso filtro intelectual de nuestra percepción del mundo contemporáneo (11).
\end{abstract}

Cabe señalar que las problemáticas sociales identificadas a través del concepto de desarrollo se delimitan mediante la especialización de enfoques disciplinarios surgidos en el seno de la participación de la ciencia en la semántica desarrollista (antropología, sociología, economía, política). Con ello, el desarrollo adquiere variadas acepciones, entre las cuales encontramosal desarrollo territorial ${ }^{3}$. ParaBoisier (1999) el desarrollo territorial es un concepto que implica la idea de contenedor, un espacio

Entre sus variantes podemos nombrar al desarrollo local, el desarrollo regional, endógeno, descentralizado, cada uno de los cuales reclama el tratamiento de problemáticas particulares en función de un campo reflexivo especializado y delimitado. geográfico delimitado en torno a una cualidad especial exaltada por medio de dispositivos político-administrativos. Vale decir, la idea de modelo de desarrollo territorial contempla una base sobre la cual se articula la comunicación de futuro promisorio y comprensivo. Dicha base se refiere a la particularidad que ofrece el territorio, como por ejemplo, los atractivos naturales y culturales que se dispongan para la comunicación turística, obteniéndose, de este modo, un modelo de desarrollo territorial turístico (Callizo 1991; Santana 1997).

Al observar al turismo articulando un modelo de desarrollo territorial, veremos que este se atribuye la construcción discursiva del territorio, organizándolo en función de competencias particulares que permitan relevar y llevar a cabo el viaje de ocio. Este proceso es altamente selectivo, toda vez que la comunicación turística actuará sublimando aquellas dimensiones territoriales susceptibles de visita turística, esto es, que favorezcan el viaje de ocio, excluyendo así aquellas dimensiones que no lo permiten. Así, la segregación socio-espacial de un territorio turístico puede comprenderse como parte de la dimensión excluida de la comunicación turística, o como la huella que va dejando la instalación y despliegue de la semántica turística en un territorio determinado, entendiendo que solo algunos elementos territoriales participan en la comunicación turística, mientas que otros simplemente no lo hacen.

Si lo anterior es observado desde la comunicación turística, la inclusión/exclusión de elementos territoriales susceptibles de visita turística guarda absoluta lógica con elevar las probabilidades de visita turística o de probabilizar el viaje de ocio a través del medium turismo. Pero si lo observamos desde 
un modelo de desarrollo territorial, es decir, desde la 'comunicación de un futuro promisorio' $y$ 'comprensivo de lo social articulada a través de una competencia territorial', el fenómeno deja de ser trivial, puesto que la semántica del desarrollo, a diferencia del medium turismo, sí incorpora a la población local -incluida la población segregada- por medio del despliegue de diversas expectativas de rol en función de la construcción turística del territorio. Si un territorio define su modelo de desarrollo territorial sobre la base del turismo, la principal implicancia será que la promesa de bienestar social en la población residente se sustentará en la medida que se probabilice el viaje de ocio o, dicho de otra manera, el medium turismo se planteará al servicio de la comunidad y sus problemáticas locales.

Por ende, si un modelo de desarrollo territorial se plantea desde el medium turismo, será posible observar en este la comunicación de un futuro promisorio para la población residente mediante la exaltación de dimensiones territoriales construidas para enfrentar exitosamente al turista en su doble ámbito de contingencia (turistear/vacacionar). Así, una expresión como la segregación socio-espacial en contextos de vocación turística se puede entender como la consecuencia paradójica de un modelo de desarrollo territorial definido en función del turismo, pues estará sujeta a una permanente tensión entre la semántica del desarrollo (que la incluye) y el medium turismo (que la excluye)

\section{Conclusión}

Las reflexiones teóricas presentadas en este artículo no pretenden dar una lectura definitiva al fenómeno de la segregación socio-espacial en contextos de vocación turística. Con ellas se pretendió ofrecer tan solo una alterativa de observación a uno de los problemas suscitados en torno a la planificación turística del territorio que, por lo general, se tiende a caracterizar siguiendo el primado de dimensiones materiales. Así, se ha establecido la correlación del turismo con el viaje de ocio. Se ha podido, además, fundamentar la necesidad de mayor abstracción teórica para caracterizar un fenómeno que emerge en la sociedad funcionalmente diferenciada (Luhmann 1997) y que, por ende, demanda enfoques de observación que permitan atender a su especificidad en el marco de la complejidad social. En este camino, siguiendo a Farías (2008), se caracterizó al turismo como medium cuya función es la probabilización del viaje de ocio. Esta propuesta se aleja de consideraciones objetuales, permitiendo poner al turismo en relación con las funciones de los sistemas funcionales (Osorio 2004), y ya no solo distinguiéndolo desde un primado de criterios económico-productivos y subjetivos.

De igual manera se ha caracterizado la semántica del desarrollo poniendo de relieve su articulación a través de la dimensión temporal. En efecto, el concepto de desarrollo emerge hacia la mitad del siglo XX como variable contemporánea de la modernización con la función de transferir al futuro la posibilidad de comprensión de la estructura de la sociedad.

Con todo, a través de las presentes reflexiones es posible observar que, mientras la semántica del desarrollo no establece distinciones especiales para excluir segmentos sociales de su comunicación, el medium turismo sí lo hace, mostrándose indiferente respecto de aquellos elementos de su entorno que no funjan como atractivos. Así, la pregunta por la segregación 
socio-espacial en contextos de vocación turística plantea una paradoja suscitada en la naturaleza de las funciones del medium turismo y de la semántica del desarrollo, puesto que, dada la articulación del medium turismo en torno a la generalización simbólica del atractivo, la segregación socio-espacial no participa de su comunicación. No obstante, sí lo hace en la semántica del desarrollo, toda vez que esta posee características más bien totalizadoras con el territorio, no estableciendo criterios de exclusión específicos en su comunicación. De este modo, la segregación socio-espacial en contextos de vocación turística puede observarse como un proceso de actualización de sentido que está en permanente tensión entre el medium turismo y la semántica del desarrollo.

Observar el fenómeno de esta manera permitiría abordar la precariedad social en contextos turísticos ya no solo desde el turismo propiamente tal, sino además desde la comunicación de futuro promisorio y comprensivo que ha escogido al turismo como la competencia territorial que articula la posibilidad de procesar los dilemas locales.

\section{Bibliografía}

Acuña, Á. 2012. "Tapati Rapa Nui. La reconstrucción de un espacio mítico en contexto turístico". En Asensio, R. y Pérez, B. (Eds.). ¿El turismo es cosa de pobres? patrimonio cultural, pueblos indígenas y nuevas formas de turismo en América Latina. Tenerife: Pasos-IEP.

Alburquerque, F. 2004. "Desarrollo económico local y descentralización". Revista de la CEPAL 82: 157-171.

Antón, S. 1998. "La ciudad turística. De la conquista del viaje a la reestructuración de la ciudad turística". Documents d'Analisis Geogràfica 32: 17-43.

Aragón, M. 2013. "Lo efímero y la ciudad turística. A propósito de los haceres y lugares del turismo en el espacio urbano". Diálogos Latinoamericanos 21: 111-124.

Arnold, M. 2012. "El debate sobre las desigualdades contemporáneas: ¿puede excluirse la exclusión social?" MAD 27: 34-43.

Arnold, M. 2010. "Constructivismo sociopoiético". MAD 23: 1-8.

Benko, G. 1998. "El impacto de los tecnopolos en el desarrollo regional. Una revisión crítica". EURE 24(73): 55-80.

Boisier, S. 2003. "¿Y si el desarrollo fuese una emergencia sistémica?" Reforma y democracia 27: 1-24.

. 2001. "Biorregionalismo, la última versión del traje del emperador". Territorios 5: 115-142

1999. Desarrollo (Local): ¿De qué estamos hablando?

Documento comisionado por la Cámara de Comercio de Manizales, Medellín.

Bourdieu, P. 1998. La distinción. Criterios y bases sociales del gusto. Madrid: Taurus.
Boyer, M. 2002. "El turismo en Europa, de la edad moderna al siglo XX". Historia contemporánea 25: 13-31.

Burke, P. 1997. "The invention of leisure in early modern Europe: Reply". Past \& Present 156: 192-197.

Burke, P. 1995. "The invention of leisure in early modern Europe". Past \& Present 146: 136-150.

Cadenas, H. 2012. "La desigualdad de la sociedad. Diferenciación y desigualdad en la sociedad moderna". Persona y sociedad 26(2): 51-77.

2006. "Derecho y sociedad: ¿es posible la integración social mediante el derecho?" En Farías, I. y Ossandon, J. (Eds.). Observando sistemas: nuevas apropiaciones y usos de la teoría de Niklass Luhmann. Santiago: RIL.

Callizo, J. 1991. Aproximación a la geografía del turismo. España: Síntesis.

Comisión Económica para América Latina y el Caribe (CEPAL). 1996. Fortalecer el desarrollo. Interacciones entre macro y microeconomía. Santiago: CEPAL.

1991. El desarrollo sustentable: transformación productiva, equidad y medio ambiente. Santiago: CEPAL.

Clarke, S., Gaile, G. y Saiz, M. 1999. "Estrategias de desarrollo en áreas deprimidas de Estados Unidos". Territorios 1: 43-75.

Corsi, G., Espósito, E. y Baraldi, C. 1996. Glosario sobre la teoría social de Niklas Luhmann. México D.F: Anthropos, Universidad Iberoamericana, ITESO.

De Esteban, J. 2008. Turismo cultural y medio ambiente en destinos urbanos. Madrid: Universidad Rey Juan Carlos.

Díaz, A. 2006. Pobreza y precariedad urbana en México. Santiago: CEPAL. 
Díaz, F. 2004. "Turismo, urbanización y cambio social”. Revista argentina de sociología 2(2): 115-127.

Díaz, F. y Lourés, M. 2008. "La globalización de los mercados inmobiliarios. Su impacto sobre la Costa Blanca". Ciudad y territorio 155: 77-92.

Dockendorff, C. 2013 "Antihumanismo o autonomía del individuo ante las estructuras sociales: la relación individuosociedad en la teoría de Niklas Luhmann". Cinta de moebio 48: 158-173.

Enríquez, J. 2010. "El escenario turístico en Puerto Peñasco. Efectos sociales y urbanos". Diálogos latinoamericanos 17.

Escobar, A. 2007. La invención del Tercer Mundo. Construcción y deconstrucción del desarrollo. Bogotá: Norma.

Elias, N. y Dunning, E. 1992. Deporte y ocio en el proceso de la civilización. México D.F: FCE.

Farías, F. 2008. Touring Berlin. Virtual destination, tourist communication and the multiply city (Tesis para optar al grado de Doctor). Alemania: Universidad de Humboldt.

Farías, I. 2014. "Virtual attractors, actual assemblages: How Luhmann's theory of communication complements actor-network theory". European Journal of Social Theory 17(1): 1-18.

Fernández, L. 1991. Historia general del turismo de masas. Madrid: Alianza.

Ferro, S. 2011. La Tierra en Sudamérica. La Paz: IPDRS.

Flores, A. 2005. El sistema municipal y la superación de la pobreza y precariedad urbana en el Perú. Serie Medio Ambiente y Desarrollo, CEPAL 120.

Fontes, D. y Marinho, J. 2011. "Turismo, políticas y desigualdades en la Villa Ponta Negra - Brasil". Estudios y perspectivas en turismo 20: 1281-1294.

Garín, A., Salvo, S. y Bravo, G. 2009. "Segregación residencial y políticas de vivienda en Temuco: 1992-2002". Revista de Geografía Norte Grande 44: 113-128.

Gordon, B. 2002. "El turismo de masas: un concepto problemático en la historia del siglo XX". Historia Contemporánea $25,125-156$

Gómez, J. 2004. "Turismo y patrimonio. Conflicto social y modelo de desarrollo urbano en Valencia, España". Estudios y perspectivas en turismo 13, 69-88.

Ibarra, R. 2007. "Segregación socio-espacial en ciudades turísticas. El caso de Canela (RS), Brasil”. Estudios y perspectivas en turismo 16(2): 195-211.

Inostroza, G. 2008. "Aportes para un modelo de gestión sostenible del turismo comunitario en la región andina". Gestión turística 10: 77-90.

Izuzquiza, I. 2008. La sociedad sin hombres. Niklas Luhmann o la teoría como escándalo. Barcelona: Anthropos.

Jafari, J. 1994. "Structure of Tourism: Three Models". En Witt, $S$ y Moutinho, L. (Eds.) Tourism

Marketing and Management Handbook (2nd Edition). Nueva York: Prentice Hall. 1-7.

Jarrassé, D. 2002. "La importancia del termalismo en el nacimiento y desarrollo del turismo en Europa del siglo XIX".
Historia contemporánea 25: 33-49.

Juárez, D. 2012. Ecoturismo comunitario en México: dos casos de éxito. En Asensio, R. y Pérez, B. (Eds.). ¿El turismo es cosa de pobres? patrimonio cultural, pueblos indígenas y nuevas formas de turismo en América Latina.). Tenerife: Pasos-IEP.

Laborde, P. 2002. "Nacimiento y desarrollo del turismo en Biarritz durante el segundo imperio". Historia contemporánea 25: 51-64.

Lafargue, P. 1907. The right to be lazy and other studies. California: California University.

Larrinaga, C. 2002. "El turismo en la España del siglo XIX". Historia contemporánea 25: 157-179.

López, E. 2002. "Orígenes y formación del derecho al descanso semanal". Estudios doctrinales s/n: 1-32.

Luhmann, N. 2010. Los derechos fundamentales como institución. Aportación a la sociología política. México D.F: Universidad iberoamericana.

Luhmann, N. 2007. La sociedad de la sociedad. México D.F: Herder.

1998. Complejidad y modernidad: de la unidad a la diferencia. Madrid: Trotta.

Luhmann, N 1997. Observaciones de la modernidad. Racionalidad y contingencia en la sociedad moderna. Barcelona: Paidós.

Mantecón, A. 2008. La experiencia del turismo. Un estudio sociológico sobre el proceso turístico residencial. Barcelona: Icaria.

Mazón, T., Huete, R. y Mantecón, A. 2009. "Tourism dependence and host community perceptions. Notes on the social exchange theory". Tourism \& management studies 5: 25-36.

Marengo, C. 2004. "Una aproximación a la segregación residencial, como punto de partida en la formulación de políticas". INVI 50(19): 167-183.

Meyer, R. 2013. "Revisando la historia de las teorías del desarrollo". CUHSO 23(1): 55-91.

Molina, S. y Rodríguez, S. 2005. Planificación integral del turismo. Un enfoque para Latinoamérica. México D.F: Trillas.

Nassehi, A. 2011. "La teoría de la diferenciación funcional en el horizonte de sus críticas". MAD 24: 1-29.

Ojeda, L. 2012. "El patrimonio inmaterial P'urhué y el turismo cultural. Reflexiones en torno a un festival étnico". En Asensio, R. y Pérez, B. (Eds.). ¿El turismo es cosa de pobres? patrimonio cultural, pueblos indígenas y nuevas formas de turismo en América Latina. Tenerife: Pasos-IEP.

Osorio, M. 2007. "El carácter social del turismo. Un análisis sistémico sobre su complejidad". Estudios y perspectivas en turismo 16(4): 464-492.

2004. La complejidad del turismo. Ponencia presentada al VI Congreso de Investigación Turística. Universidad Autónoma del Estado de México.

Pérez, F. y Labraña, J. 2013. "Hacia la observación de una sociedad venidera: una entrevista con Dirk Baecker". MAD 29: 82-91. 
Pérez, E. 2010. "Segregación socioespacial en ciudades turísticas. El caso de Puerto Vallarta". Región y sociedad 23(49): 143-176.

Robles, F. 2000. "Contramodernidad y desigualdad social. Individualización e individuación, inclusión/exclusión y construcción de identidad. La necesidad de una sociología de la exclusión". En Robles, F. (Ed.). El desaliento de la modernidad. Molestias, irritaciones y frutos amargos de la sociedad del riesgo. Santiago: RIL. 47-87.

Rodríguez, D. y Arnold, M. 2007. Sociedad y teoría de sistemas. Santiago: Editorial Universitaria.

Sabatini, F. 2006. La segregación social del espacio en las ciudades de América Latina. Banco Interamericano de Desarrollo.

Sabatini, F., Cáceres, G. y Cerda, J. 2001. "Segregación residencial en las principales ciudades chilenas: tendencias en las tres últimas décadas y posibles cursos de acción". EURE 27(82): 21-42.

Santana, A. 2008. "El turismo cultural iun negocio responsable?" Estudios y perspectivas en turismo 17: 272-294.

Santana, A. 1997. Antropología y turismo ¿nuevas hordas, viejas culturas? Barcelona: Ariel.

Segovia, O. y Jordan, R. 2005. Espacios públicos urbanos, pobreza y construcción social. Serie Medio Ambiente y Desarrollo, CEPAL 122.

Serrano, R, et al. 2012. "La complejidad, expresión de nuestro tiempo: el turismo desde los sistemas complejos". CULTUR 6(1): 5-24.

Sue, R. 1987. El ocio. México D.F: FCE.
Schaerer, J. y Dirven, M. 2001. El turismo rural en Chile. Experiencias de agroturismo en las regiones del Maule, La Araucanía y Los Lagos. Serie Desarrollo Productivo, CEPAL 112.

Torche, F. 2006. "Una clasificación de clases para la sociedad chilena". Revista de sociología 20: 15-43.

Turner, L. y Ash, J. 1991. La horda dorada. Madrid: Endimión. Vásquez, D., et al. 2013. "El turismo desde el pensamiento sistémico". Investigaciones turísticas 5: 1-28.

Vásquez, A. 1996. "Desarrollos recientes de la política regional. La experiencia europea". EURE 23(65): 101-114.

Veblen, T. 2004. Teoría de la clase ociosa. México D.F: FCE.

Violá, A. 2000. Antropología del desarrollo. Teorías y estudios etnográficos en América Latina. Barcelona: Paidós.

Von Bertalanffy, L. 1989. Teoría general de los sistemas. México D.F: FCE.

Walton, J. 2002. "Aproximación a la historia del turismo en el Reino Unido. Siglos XVIII-XX”. Historia contemporánea 25: 65-82.

Weber, M. 1991. La ética protestante y el espíritu del capitalismo. México D.F: Premia.

Yaukhana, E. 2012. "From exploitation to participation? Tourism and handicraft in rural Yucatán". En Asensio, R. y Pérez, B. (Eds.). ¿El turismo es cosa de pobres? patrimonio cultural, pueblos indígenas y nuevas formas de turismo en América Latina. Tenerife: Pasos-IEP.

Zunino H., Hidalgo, R. y Marquardt, E. 2011. "Vivienda Social y segregación espacial en la ciudad de Pucón, Chile: entre el enclaustramiento y la integración con el hábitat turístico". INVI 26: $15-55$ 
